\title{
A Universidade, a educação de adultos e a inclusão social
}

\section{The University, adult education and social inclusion}

\author{
Maria Corrêa, Antônio Rodrigues, Armando Loureiro, João Coqueiro, Manoel Oliveira, Sílvia Silva \\ Universidade de Trás-os-Montes e Alto Douro
}

\begin{abstract}
Resumo
Esse estudo tem como meta discorrer sobre o papel da Universidade, a Educação de Adultos e a Inclusão Social. O MEC/CAPES está investindo com políticas públicas voltadas para esse nível de ensino, as pessoas que não puderam estudar podem retornar à escola com as opções: graduação e formação contínua. Nesse contexto a $\mathrm{EaD}$ através da Universidade Aberta do Brasil tornou-se uma das alternativas educacionais capazes de ajudar as pessoas que necessitam de qualificação a nível superior. É importante que a sociedade tenha consciência do papel que a EaD tem na Educação de Adultos.

Palavras-chave: Universidade; Inclusão Social; Educação de Adultos.
\end{abstract}

\begin{abstract}
This study aims to discuss the role of the University, Adult Education and Social Inclusion. The MEC / CAPES is investing with public policies aimed at this level of education, people who were not able to study can return to school with the options: graduation and continuing education. In this context, EAD through the Open University of Brazil has become one of the educational alternatives capable of helping people who need qualification at a higher level. It is important that society is aware of the role that ED has in Adult Education.
\end{abstract}

Keywords: University; Social inclusion; Adult Education.

\section{Introdução}

A análise das políticas públicas educacionais voltadas para a Educação de Adultos é relevante no Brasil, nos ajuda a perceber que essa modalidade de ensino permite às pessoas que não tiveram meios ou puderam concluir seus estudos a merecida oportunidade de estudar. No Brasil ocorreu um processo de reformas educacionais que resultou na construção dos compromissos éticos, políticos e sociais firmados pela Constituição Federal de 1988.

Num contexto, em que se ressalta a importância da Educação de Adultos não se pode esquecer a relação entre a sociedade e a universidade deve ser a melhor possível, para que a universidade possa provocar a comunidade a se envolver e participar da mesma e com isso motivar a mesma a estimular o desenvolvimento local e comunitário na região onde a instituição está localizada.
Papel das universidades no desenvolvimento social e comunitário

A Universidade é uma das instituições mais importantes da atualidade, tem uma grande responsabilidade perante a sociedade e é uma daquelas a quem mais se têm exigido resultados positivos na comunidade onde a mesma se insere. Exige-se maior participação da Universidade na resolução dos problemas na sociedade.

Para Loureiro, (1999): “A problemática da relação entre Universidade e Sociedade tem vindo a ser discutida há muito tempo. Desde a formação daquela, na Idade Média, que se pede resposta para determinadas exigências às quais foi respondendo: as reflexões teológicas ocorridas no seu interior reflectiam, de algum modo, às preocupações intelectuais daqueles séculos.

De acordo com os estudos de Loureiro, (1999) a Universidade é uma organização complexa, que tem características próprias que a distingue das demais organizações e isto ocorre porque existe uma forte política na base das tomadas de decisões, com uma estrutura fragmentada e descentralizada, o que faz com que o poder esteja demasiadamente espalhado e isso provoca uma dificuldade em medir a produção na ação organizacional e não existem padrões de desempenho e compromisso com resultados.

Para Nogueira, (2008): “A universidade existe para produzir conhecimento, gerar pensamento crítico, organizar e articular os saberes, formar cidadãos, profissionais e lideranças intelectuais". O desempenho dessas nobres e decisivas funções, porém, não é algo que se resolva no plano abstrato, mas com atividades práticas.
A função da Universidade
A universidade desempenha importantes papéis para o desenvolvimento humano, regional e sustentável na sociedade contemporânea. Ela tem a missão não apenas de possibilitar aos alunos a obtenção de um diploma, ofertar um curso de extensão ou formação técnica ou profissional para que a pessoa consiga um emprego e remuneração satisfatória, mas deve ser capaz de produzir novos conhecimentos e aplicá-los à realidade social, considerando a necessidade de ser acessível a toda a sociedade, em todos os níveis sociais para que haja 
inclusão social, exercendo tanto uma função social quanto política de desenvolvimento sustentável. (Luckesi, 1998).

A universidade tem o dever de retribuir o investimento que recebe da comunidade, desenvolvendo estudos, pesquisas e projetos de extensão compatíveis com as reais necessidades da população em benefício comum, isto é, ela deve contribuir para solucionar os atuais problemas da sociedade. Outra função da universidade é auxiliar os alunos para que eles tenham uma opinião crítica diante da realidade social para que haja um avanço científico, tecnológico e cultural, isto é, a universidade tem como função o dever de estar comprometida com a construção de uma sociedade mais justa e igualitária.

Tem a função de absorver demandas e expectativas sociais variadas, às quais precisa corresponder, e ao mesmo tempo agir para propor pautas e agendas, contribuir para a construção da autoconsciência social, alargar fronteiras culturais e submeter à crítica a realidade, as estruturas sociais $\mathrm{e}$ as relações de dominação. Por isso funciona melhor quanto mais republicana e democrática for, o Estado com o qual se relaciona.

As universidades e equivalentes instituições de ensino superior formam as futuras gerações de cidadãos e possuem conhecimentos de especialidade em todos os campos da investigação, tanto em tecnologia como nas ciências naturais, humanas e sociais.

Para Silva, (2011) "A extensão universitária é uma forma de interação que deve existir entre a universidade e a comunidade na qual ela está inserida, uma espécie de ponte permanente entre a universidade e os diversos setores da sociedade. Funciona como uma via de duas mãos em que a universidade leva conhecimentos e/ou assistência à comunidade e recebe dela influxos positivos em forma de retroalimentação, tais como suas reais necessidades, anseios e aspirações.

Além disso, a universidade aprende com o saber dessas comunidades". A autora demonstra em suas palavras que a extensão universitária é uma forma de interação entre a universidade e a sociedade e que a mesma deve produzir e adquirir conhecimentos, propor soluções para o desenvolvimento social e comunitário.

Um país só é desenvolvido socialmente quando seus habitantes têm qualidade de vida, para que se saiba se essa população tem um ótimo nível de vida é necessário comparar entre as populações de outros países para se avaliar o nível de desenvolvimento social de um país.

Nos anos 50 a ONU (Organização das Nações Unidas) passou a divulgar o desenvolvimento comunitário como: "processo através do qual cada povo participa do planejamento e da realização de programas que se destinam a elevar o padrão de suas vidas. Isso implica na colaboração indispensável entre os governos e o povo para tornar eficazes os esquemas de desenvolvimento viáveis e equilibrados" (Ammann, 1981).

No Brasil, os primeiros projetos de desenvolvimento comunitário se desenvolveram na década de 1940 com a realização de convênios na produção de alimentos, educação rural e industrial.

O papel das universidades neste desenvolvimento social e comunitário é relevante, pois são elas que promovem ações voltadas para que ocorra esse desenvolvimento tão desejado por toda a população brasileira.

\section{A educação de adultos no brasil}

A história da Educação de Adultos no Brasil primeiro esteve ligada à formação profissional, é nesse contexto que entra a $\mathrm{EaD}$, capacitando pessoas adultas para exercer certas atividades ou dominar determinadas habilidades, sempre motivadas por questões de mercado, depois foi que se passou a vê-la como uma alternativa educacional que poderia resolver muitos problemas no país, tais como a extensão territorial, a falta de estradas, a falta de universidades, de equipamentos e de professores qualificados.

Para Moran, a educação a distância é uma alternativa viável de educação e isso ocorre desde o a última década do século XX no Brasil, após a promulgação da LDB Lei $\mathrm{n}^{\circ}$ 9.394/1996. "Estamos caminhando para uma aproximação sem precedentes entre os cursos presenciais (cada vez mais semipresenciais) e os a distância. Os presenciais terão disciplinas parcialmente a distância e outras totalmente a distância. [...] Teremos inúmeras possibilidades de aprendizagem que combinarão o melhor do presencial (quando possível) com as facilidades do virtual. Em poucos anos dificilmente teremos um curso totalmente presencial. (Moran, 2005)."

A história da EaD no Brasil tem seu marco inicial com a fundação da Rádio Sociedade do Rio de Janeiro em 1923, por Roquete Pinto, que em sua programação transmitia programas de literatura, de línguas, literatura infantil e sobre assuntos de interesse comunitários, ou seja, iniciou-se por rádio difusão.

O início dos anos 1960, a Diocese de Natal (Rio Grande do Norte) criou as escolas radiofônicas, que deram origem ao Movimento de Educação de Base (MEB), cuja "preocupação básica era alfabetizar e apoiar os primeiros passos da educação de milhares de jovens e adultos, principalmente da região Norte e Nordeste do Brasil".

Nos anos 70, o destaque foi o Projeto Minerva, integrado ao Ministério da Educação, Fundação Padre Anchieta e Fundação Padre Landell de Moura (FEPAM), fundamentados na Lei $n^{\circ} 5.692 / 69$ que enfatizava a educação de adultos. O Projeto Minerva transmitia em rede nacional, através de rádio e televisão, seu objetivo era preparar alunos para os exames supletivos de Capacitação Ginasial e Madureza Ginasial. Em 1978 foi criado o Telecurso $2^{\circ}$ grau, através de uma parceria da Fundação Padre Anchieta e Fundação Roberto Marinho.

Em 1979 houve a criação da Fundação Centro Brasileiro de Televisão Educativa (FCTVE), utilizando programas de televisão no projeto Movimento Brasileiro de Alfabetizacão (MOBRAL). Neste mesmo ano, a Coordenacão de Aperfeicoamento do Pessoal de Ensino Superior (CAPES) faz experimentos de formacão de professores do interior do país através da implementação da Pós-Graduacão Experimental a Distância. Já em 1984, em São Paulo, é criado o Projeto Ipe, cujo objetivo era o de aperfeicoar professores para o Magistério de $1^{\circ}$ e $2^{\circ}$ graus. 
No contexto da legislação em EaD, é notório que as bases legais para essa modalidade de educação surgiram tardiamente comparado com o seu aparecimento. A partir de 20 de dezembro de 1996, com a promulgação da Lei de Diretrizes e Bases da Educação Nacional (LDBEN), Lei $n^{\circ}$ 9.394/96, a Educação a Distância passa a ser regulamentado pelo Decreto $\mathrm{n}^{\circ} 5.622$, publicado no Diário Oficial da União em 20 de dezembro de 2005. A Resolução $\mathrm{n}^{\circ} 1$ de 03 de abril de 2001, do Conselho Nacional de Educação (CNE) estabeleceu as normas para o funcionamento de cursos da pós-graduação.

Com todas essas regulamentações foram adotados alguns critérios para esse nível de ensino, tais como: para a educação básica, de acordo com o Art. $2^{\circ}$ do Decreto $n^{\circ}$ 2.498/98, os cursos à distância com certificação ou diploma de conclusão do ensino fundamental para jovens e adultos, de ensino médio, da educação profissional e de graduação são ofertadas por intermédio de instituições públicas ou privadas especificamente credenciadas para esse fim.

Quanto à oferta de cursos à distância, o Decreto $\mathrm{n}^{\circ}$ 2.561/98 vem delegar competências às autoridades integrantes dos sistemas de ensino, na qual trata o Art. $8^{\circ}$ da LDB, em que promove os atos de credenciamento de instituições localizadas no âmbito de suas respectivas atribuições.

Percebemos a importância de maiores investimentos na educação de adultos, já que é através desses investimentos que podemos melhorar os índices de analfabetismo e qualificação das pessoas tanto a nível médio quanto em nível superior.

\section{Educação de adultos como instrumento de inclusão}

A Educação de Jovens e Adultos (EJA), a partir da Lei de Diretrizes e Bases da Educação Nacional (LDBEN), lei $\mathrm{n}^{\circ} 9.394$ de1996 (BRASIL, 1996) passou a ser uma modalidade da educação básica nas etapas do ensino fundamental e médio. Já está legalizada, e quando há vontade de mudar o quadro de analfabetismo existente no país, com medidas certas e de incentivo para melhorar a educação dessas pessoas que não tiveram oportunidade de estudar na idade certa essas políticas públicas terão um caráter de inclusão social e pessoal.

Na LDBEN (Lei de Diretrizes e Bases da Educação Nacional) Lei 9.394/96, em seu artigo 37 e inciso primeiro consta que: "A educação de jovens e adultos será destinada àqueles que não tiveram acesso ou continuidade de estudos no ensino fundamental e médio na idade própria. $\S 1^{\circ}$ - Os sistemas de ensino assegurarão gratuitamente aos jovens e aos adultos, que não puderam efetuar os estudos na idade regular, oportunidades educacionais apropriadas, consideradas as características do alunado, seus interesses, condições de vida e de trabalho, mediante cursos e exames (Brasil, 1996).

De acordo com o artigo citado acima percebemos que as leis já favorecem essas pessoas, porém percebemos que faltam ações dinâmicas e eficazes para que se obtenha uma educação que tenha como objetivo servir de instrumento de inclusão. De acordo com as Diretrizes Curriculares Nacionais para a Educação de Jovens e Adultos, a EJA: '[...] considerará as situações, os perfis dos estudantes, as faixas etárias e se pautará pelos princípios de eqüidade, diferença e proporcionalidade na apropriação e contextualização das diretrizes curriculares nacionais e na proposição de um modelo pedagógico próprio, de modo a assegurar: I - quanto à equidade, a distribuição específica dos componentes curriculares a fim de propiciar um patamar igualitário de formação e restabelecer a igualdade de direitos e de oportunidades face ao direito à educação... (Brasil)",

Se considerarmos o perfil dos alunos da EJA observaremos que se pode realizar um trabalho de qualidade baseado em suas próprias histórias de vidas, tornando seus conhecimentos empíricos em conhecimentos científicos, sistematizados e capazes de serem úteis em suas vidas.

Segundo Freire (1987) o direito à educação não se reduz somente a estar na escola, mas sim em aprender. E, aprender para tomar consciência de seu estado de opressão, para que assim possa se libertar daqueles que o oprimem Em geral, os estudantes da EJA possuem uma considerável experiência de vida que deve ser respeitada e preservada. E, já aprenderam diferentes coisas em diferentes contextos pela necessidade que a vida lhes impõe.

\section{Apresentação e análise dos dados}

Essa pesquisa ocorreu no município de Nina Rodrigues - Maranhão, localizada na região Nordeste do Brasil. É um município pequeno, com cerca de quinze mil habitantes e em 2009 foi inaugurada a Universidade Aberta do Brasil. Desde a criação do Polo Tecnológico UAB II de Nina Rodrigues, a instituição funcionou com os cursos de Administração Pública, Filosofia, Pedagogia, Matemática, especializações latu sensus e alguns cursos de formação contínua voltados para adultos. que necessitavam urgentemente se qualificar de acordo com as exigências legais

Em 2017, foram implantados novos cursos de Administração, Pedagogia, Geografia, Matemática, Letras/Português e Ciências da Computação, com um total de 310 alunos matriculados e estudando os respctivos cursos de graduação.

O método utilizado neste trabalho foi uma revisão bibliográfica e um estudo de caso, com quatro participantes, dentre eles, dois formandos adultos e da $\mathrm{EaD}$ e oriundos da UAB local e dois empresários locais do ramo de hotelaria e alimentação, os quais discorrem sobre o antes e o depois da implatação da UAB.

Neste estudo de caso as perguntas foram voltadas para o antes e o depois da criação da UAB no município. E vamos caracterizar os formandos em F1 e F2 e os empresários de EH empresário de hotelaria e EA empresário de alimentação e serão expostas através de tabelas.

A primeira pergunta para os formandos foi a seguinte:

$1^{\mathrm{a}}$ ) Comente sobre sua vida e profissão antes de se formar através da modalidade $\mathrm{EaD}$ na UAB de Nina Rodrigues. 
Tabela 1.

Antes da $U A B$

\begin{tabular}{|c|c|}
\hline Formando 1 & Formando 2 \\
\hline $\begin{array}{l}\text { Era efetivo, porém } \\
\text { ganhava menos que meus } \\
\text { colegas graduados, sem } \\
\text { contar que a LDB Lei no } \\
\text { 9.394/96 exigia que todos os } \\
\text { docentes se graduassem, eu } \\
\text { já havia perdido as } \\
\text { esperanças de ter o curso } \\
\text { superior, meu minguado } \\
\text { salário não permitia que eu } \\
\text { fosse estudar numa } \\
\text { instituição privada. Em } \\
2009 \text { quando inauguraram a } \\
\text { UAB aqui em Nina } \\
\text { Rodrigues e eu fui aprovado } \\
\text { no vestibular e de uma } \\
\text { universidade pública eu nem } \\
\text { acreditava, era a realização } \\
\text { dos meus sonhos. }\end{array}$ & $\begin{array}{l}\text { Não era concursada, as } \\
\text { vezes trabalhava como } \\
\text { contratada e por apenas } 10 \\
\text { meses ganhando apenas o } \\
\text { salário mínimo vigente. } \\
\text { Dependia da vontade política } \\
\text { e não conseguia planejar } \\
\text { estudar em uma universidade } \\
\text { pública o que ganhava no } \\
\text { contrato era muito pouco e } \\
\text { ainda tinha de economizar } \\
\text { para quando estivesse sem } \\
\text { trabalho o que ocorria } \\
\text { constantemente. Ao ser } \\
\text { aprovada no vestibular da } \\
\text { UAB foi a maior alegria que } \\
\text { senti, perdendo apenas para o } \\
\text { momento da formatura e eu } \\
\text { tocar no meu diploma. }\end{array}$ \\
\hline
\end{tabular}

Como vimos, o antes da UAB ser implantada no município era cheio de dúvidas para os profissionais da educação, o F1 era efetivo, porém ganhava pouco e a LDB exigia que ele se graduasse. Enquanto o F2 só trabalhava temporariamente, era difícil para eles sonharem com um curso de nível superior.

A segunda pergunta da entrevista foi a seguinte:

$2^{a}$ ) Após ter realizado sua formartura no Polo Tecnológico UAB II de Nina Rodrigues, relate sobre os benefícios e conquistas que você adquiriu?

Tabela 2.

Benefícios e conquistas após a formatura

\begin{tabular}{|l|l|}
\hline Formando 1 & \multicolumn{2}{|c|}{ Formando 2 } \\
\hline Entrei imediatamente com o & \multicolumn{2}{|c|}{ Fiz o concurso público } \\
pedido de promoção, no mês & em dois municípios e fui \\
seguinte já senti a diferença no & aprovada, hoje me sinto \\
meu salário, aumentou quase o & segura, adquiri a tão \\
dobro. Estudei duas & sonhada estabilidade, tenho \\
pós-graduações e estou & veículo próprio, continuei \\
pensando em estudar um & meus estudos. Pude sonhar \\
mestrado. & em ter filhos, algo \\
Os benefícios que adquiri & impossível antes na situação \\
após minha formatura foram & incerta que vivi. \\
inúmeros, posso citar alguns: & Foram tantos benefícios \\
fui promovido; passei em & que recebi da UAB que nem \\
outro concurso; atualmente & posso enumerá-los. Agora \\
ganho o triplo de antes; passei & novos cursos estão \\
a exercer cargos e funções & funcionando, e outras \\
mais específicas, ou seja, foi & pessoas também serão \\
uma bênção ter estudado em & beneficiadas. \\
nossa UAB. & \multicolumn{2}{|c|}{} \\
\hline
\end{tabular}

Nesta última pergunta sobre depois da formatura percebe-se que houve sim desenvolvimento social, intelectual e profissional, os benefícios que esses alunos obtiveram foram muitos, isto é, a Educação a Distância é realmente uma alternativa viável para solucionar muitos problemas e capaz de promover a inclusão social.

A próxima pergunta da entrevista está voltada para um empresário de hotelaria e um empresário de alimentação, e a pergunta voltada a eles será:

$\left.1^{\mathrm{a}}\right)$ Quais os benefícios que os empresários de nosso município obtiveram após a implantação da Universidade?

Tabela 3.

Benefícios obtidos após $U A B$

\section{Empresário hoteleiro}

Antes da implantação da universidade em nosso município só tínhamos um hotel, atualmente temos 5 , nos finais de semana todos os nossos quartos são ocupados por professores e familiares desses professores, alunos de outros municípios também se hospedam conosco, aumentaram os empregos e demonstrou que a universidade trás desenvolvimento social e comunitário nos locais onde está inserida.

Os dois entrevistados revelaram o antes e o depois da implantação da universidade. A vinda de professores e estudantes de outros municípios gerou renda, empregos, para muita gente. O desenvolvimento comunitário ocorre através de um processo de desenvolvimento socioeconômico que deve partir da população local e para que isso ocorra faz-se necessário que a universidade e a comunidade estejam interagindo sempre em busca de alternativas para o desenvolvimento das potencialidades daquela região. E foi o que ocorreu em nosso município, essa interação ajudou muitas famílias a terem seu próprio negócio.

Vimos nessas entrevistas o quanto é importante a educação para a sociedade contemporânea, os alunos melhoraram suas vidas intelectuais, econômicas e sociais, os empresários tiveram oportunidades de se desenvolverem, o município onde a UAB está localizado também se desenvolveu, gerou mais empregos, trabalhadores autônomos puderam sonhar com seu próprio negócio, isto é, fica comprovado que a formação contínua é capaz mudar uma realidade.

\section{Conclusão}

Nessa perspectiva, constatamos que o polo da UAB implantada no município de Nina Rodrigues, através da Educação a Distância (EaD) é capaz sim de mudar para melhor a vida de um município, qualificando seus professores e outros profissionais, provocando o tão sonhado desenvolvimento humano, econômico, intelectual e social não somente de uma classe, mas de toda a população onde a universidade está atuando.

A EA tanto no Brasil como no mundo deve ser encarada como prioridade, tendo na $\mathrm{EaD}$ uma alternativa educacional viável, que deve ser encarada como com respeito e seriedade pelo poder público e pela sociedade 
civil organizada. Contatou-se também que é somente através da educação que o povo é capaz de transformar positivamente seu mundo e dos que estão próximos. Sabemos que "a educação sozinha não trás desenvolvimento, mas sem ela não há desenvolvimento", como dizia o nosso educador Paulo Freire (1999).

Comprovamos que a Universidade tem uma importante tarefa, a de transmitir conhecimentos científicos, incentivar a pesquisa, realizar intervenções benéficas na comunidade onde está inserida, neste sentido.

\section{Referências}

Ammann, Safira Bezerra. Ideologia do Desenvolvimento Comunitário no Brasil. São Paulo, Cortez, 1981.

Brasil, Lei $n^{\circ}$ 9.394, de 20 de Dezembro de 1996. Estabelece as diretrizes e bases da educação nacional. Disponível em: http://www.planal to.gov.br/ccivil_03/Leis/L9394.htm Acesso em 17/07/2016.

Brasil, Resolução CNE/CEB n ${ }^{\circ}$ 1, de 5 de julho de 2000. Estabelece as Diretrizes Curriculares Nacionais para a Educação e Jovens e Adultos. Disponível em http://www.educacao.rj.gov.br/index5.aspx?tipo=cate g\&iditem=378\&amp; categoria=404\&amp;idsecao $=17$ 3\&spid=7 Acesso em 17/07/2016.

(Declaração de Hamburgo sobre Educação de Adultos, V Confintea, UNESCO, 1997:42).

Freire, Paulo. Pedagogia do Oprimido. 17 a Ed. Paz e Terra, 1987.

Educação como prática da liberdade. 23 ed., Rio de Janeiro: Paz e Terra, 1999.

Junior, Hélio Santiago Ramos. A função da universidade na sociedade do conhecimento.

Disponível em http://egovbrasil.blogspot.com.br/2009/03/funcao-dauniversidade-na-sociedade-do.html. Acesso em 18 de Janeiro de 2015.

Loureiro, Armando. Novos Territórios e agentes educativos em sociologia da educação: o caso da educação de adultos. Rev.. Lusófona de Educação $\mathrm{n}^{\circ}$ 20, Lisboa, 2011.

Luckesi, Cipriano et al. Fazer universidade: uma proposta metodológica. 10. ed. São Paulo: Cortez, 1998.

Moran. J. M.. Tendências da Educação online no Brasil. 2005. Disponível em http://www.eca.usp.br/prof/moran/tendencias.htm. Acesso em 10 de outubro de 2016.

Nogueira, Marco Aurélio. Qual o papel da Universidade? Lunes. 18 de fevereiro de 2008. Disponível no site: http://marxbrito.blogspot.com.br/2008/02/qual-o-pape 1-da-universidade.html Acesso em 10 de janeiro de 2015.

Oliveira, Claudia Hochheim. Qual é o Papel da Extensão Universitária? Algumas Reflexões Acerca da Relação entre Universidade Políticas Públicas e Sociedade. Anais do $2^{\circ}$ Congresso Brasileiro de Extensão Universitária Belo Horizonte - 12 a 15 de setembro de 2004. 